\title{
AS PLANTAS MEDICINAIS COMO INSTRUMENTO DE EDUCAÇÃO AMBIENTAL
}

\author{
Miguel Antonio Correa Favila ${ }^{1}$, Juarez Martins Hoppe ${ }^{2}$ (in Memorian) \\ ${ }^{1}$ Especialista em Educação Ambiental \\ 2 Prof. do Curso de Especialização em Educação Ambiental da UFSM \\ migantoniofa@ibest.com.br
}

\section{RESUMO}

Este estudo visou sensibilizar os alunos a respeito da conservação e utilização das plantas medicinais como instrumento de Educação Ambiental e, como tratamento alternativo. Entre os resultados obtidos, salienta-se que $47 \%$ acharam-se confiantes na dosagem das plantas medicinais, razão de possíveis casos de intoxicações. E apenas $8 \%$ dos entrevistados compreenderam que a Educação Ambiental está inserida na questão social e tem como finalidade última a qualidade de vida dos povos.

Palavras Chave: educação ambiental, plantas medicinais, fitoterápicos

\begin{abstract}
This study sought to sensitize the students regarding the conservation and use of the medicinal plants as instrument of Environmental, as alternative treatment. Among the obtained results, it is pointed out that $47 \%$ were confident in the dose of the medicinal plants, reason of possible cases of intoxications. And only $8 \%$ of the interviewees they just understood that the Environmental Education is inserted in the social subject and has as last purpose the quality of life of the people.
\end{abstract}

Key-Work: environmental education, medicinal plants, phytotherapy

\section{INTRODUÇÃO}

A Educação Ambiental emerge como indicador na busca pela sensibilização da população primando intensamente pelas questões ambientais, além das questões sociais, e o bem-estar da coletividade.

A crise econômica, com o alto preço dos medicamentos industrializados, e o difícil acesso da população à assistência médica e farmacêutica são os prováveis fatores responsáveis pela utilização das plantas medicinais.

Este estudo visou sensibilizar os alunos a respeito da conservação e utilização das plantas medicinais como instrumento de Educação Ambiental e, como tratamento alternativo.

Para processar as informações estimativas e coletar dados referentes à utilização das plantas medicinais, aplicou-se um instrumento na forma de questionário aos alunos do curso Técnico em Agropecuária do Colégio Agrícola de Santa Maria. 


\section{Educação Ambiental: conceitos a repensar}

A Educação Ambiental está inserida em todos os setores da sociedade, no revelar do comprometimento mantenedor dos seus defensores diante da problemática ambiental e social

Segundo Noal et al. (1998, p. 24), a Educação Ambiental deve desenvolver sua sensibilidade crítica, assim reunirá a comunidade na participação efetiva das questões ambientais de âmbito local, regional e nacional.

O conceito de Educação Ambiental vem evoluindo, uma vez que, mais Encontros Nacionais e Internacionais discutem sobre a temática ambiental.

"A complexidade ambiental não é a ecologização do mundo" (Leff, 2002, p. 205). Nesse contexto, transcende a preservação e o conservadorismo, implica numa visão holística, nas interrelações homem versus natureza, homem versus homem, em que valorizam as questões sociais, os marginalizados, os povos oprimidos, os excluídos.

\section{O Conhecimento Empírico versus Plantas Medicinais}

O conhecimento popular está baseado na transferência de informações de geração para geração, inerente à experiência acumulada, arraigados na imitação (Lakatos, 1991).

Uma evidência do conhecimento empírico é percebidos na catalogação das plantas medicinais pelos índios e caboclos.

Nesse processo, os povos indígenas estão reconstituindo suas identidades num processo que não apenas recupera sua história e sua memória, suas identidades coletivas e suas práticas tradicionais, mas também recoloca para eles, a necessidade de reconfigurar o ser diante da globalização econômica (Leff, 2002, p.216).

Muitas das pesquisas científicas têm o seu ponto de partida no conhecimento milenar dos grupos indígenas, como exemplo, cita-se o jaborandi (Pilocarpus spp.), o guaraná (Paullinia cupana H.B.K.), erva-de-bugre (Casearia sylvestris Swartz). Com o progresso e a devastação das matas, as comunidades migram para as cidades, deixando para trás a tradição no uso das plantas medicinais.

Utilizando as palavras de Castro et al. (2001, p.19):

A relação entre o conhecimento popular e o conhecimento científico pode ser enquadrada dentro da visão dialética que prevê a transformação e a educação das idéias. 0 conhecimento popular, por um lado, associado com plantas mágicas e religiosas, leva a questionamentos na tentativa de se dar uma compreensão mais racional ao método terapêutico. Por outro lado o conhecimento científico estabelece uma relação racional entre o uso das plantas medicinais e a cura das doenças. A síntese entre esses dois pontos de vista é alcançada quando os pesquisadores, em busca de novas fontes de substâncias biologicamente ativas, vão até a população para efetuarem levantamentos etnobotânicos e, a partir destes, realizarem pesquisas laboratoriais.

\section{Fator Econômico versus Conservadorismo: uma questão ambiental}

Conforme descreve Matos (1994, p.11) "A utilização de plantas medicinais nos programas de atenção primária de saúde pode se constituir numa forma muito útil de alternativa 


\section{Monografias Ambientais}

REMOA (Revista Eletrônica do Curso de Especialização em Educação Ambiental da UFSM)

terapêutica, por sua eficácia aliada a um baixo custo operacional, dada a relativa facilidade para aquisição das plantas...".

Os fitoterápicos conquistam a população numa proporção cada vez maior. Além de serem os precursores dos medicamentos alopáticos, atraem aos consumidores pelo menor preço, menor agressividade ao organismo e os resultados repercutem beneficamente.

As indústrias farmacêuticas economizam tempo e dinheiro nas etapas das pesquisas, apoderando-se dos conhecimentos empíricos dos povos indígenas ou das comunidades étnicas locais e aceleram o término de suas sínteses. Muitas vão diretamente aos bancos de dados que já existem, outras compram as plantas medicinais nos mercados da região e associam sua fitoquímica em relação ao uso popular, e algumas dirigem-se à literatura científica. (Cunha, 2001).

\section{Plantas Medicinais: numa visão prospectiva}

Segundo a Organização Mundial da Saúde - OMS, planta medicinal é qualquer planta que possua em um ou vários de seus órgãos substâncias que sejam ponto de partida para a síntese de produtos químicos e farmacêuticos.

O marco inicial, para aprimorar estudos e ter bons resultados em relação ao cultivo das plantas medicinais, constitui primeiramente o local de cultivo, tipo de solo, adubação correta, época de coleta, identificação botânica, secagem, armazenamento e conservação.

Nascimento (2001) em sinal de alerta, salienta a presença de alcalóides pirrolizidínicos nas plantas medicinais. Os alcalóides são substâncias tóxicas produzidas no processo de bio-síntese das plantas, amplamente consumidas na forma de remédios caseiros ou alimentícios. Esses alcalóides podem provocar desde a cirrose hepática ao câncer com a destruição das células do fígado. Eles foram encontrados em 23 espécies do gênero Senecio (Ex.: Senecio braziliensis - mariamole) típico do sul do país e, 32 espécies do gênero Eupathorium (Ex.: Eupathorium laevigatum mata-pasto ou cambará-falso) encontradas no sul e sudeste, cujas folhas são utilizadas com antifebrífugo

A maioria dos trabalhos científicos com plantas medicinais estão vinculados à colaboração multidisciplinar com outros segmentos da comunidade científica como farmacólogos, botânicos, químicos e toxicólogos. (Hostettmann, 1991).

\section{MATERIAIS E MÉTODOS}

Este trabalho foi desenvolvido junto ao Colégio Agrícola de Santa Maria, localizado na Universidade Federal de Santa Maria - Campus Universitário, Bairro Camobi na cidade de Santa Maria/RS, envolvendo os alunos do Curso Técnico em Agropecuária, no qual aplicou-se um questionário para sistematizar as respostas. A linha metodológica adotada foi a qualitativa, para obtenção de dados descritivos pelos entrevistados. 


\section{Monografias Ambientais}

REMOA

(Revista Eletrônica do Curso de Especialização em Educação Ambiental da UFSM)

\section{RESULTADOS E DISCUSSÃO} Ambiental.

Nesse questionário elaboraram-se questões sobre o uso de plantas medicinais e Educação

Questão 1, Possue alguma espécie de planta medicinal em casa?

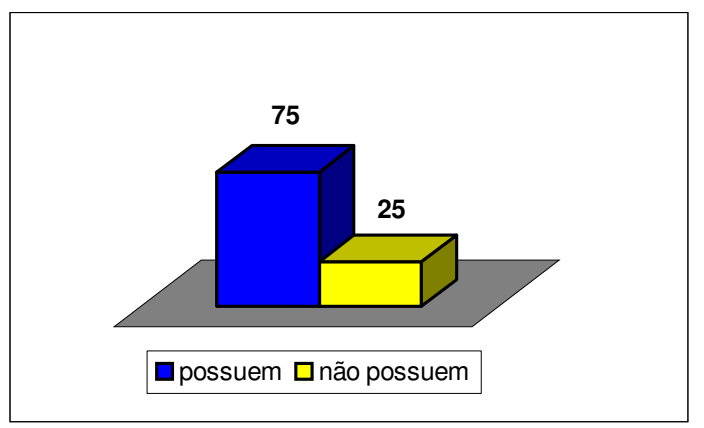

Figura 1. Quantitativo de posse das plantas medicinais

Considerando os dados acima, constata-se que a tradição popular na utilização das plantas medicinais está presente na maioria das residências. A esse fato atribui-se a questão cultural em que os conhecimentos são transmitidos de geração para geração, no auxílio da terapêutica tradicional.

Cabe salientar ainda que os remédios caseiros são adotados com uma boa credibilidade entre os membros das comunidades, no desenvolvimento de tratamentos caseiros, com a permuta de informações (Simões et al., 1999).

Questão 2, Quando se sente doente, recorre primeiramente aos medicamentos tradicionais ou as plantas medicinais?

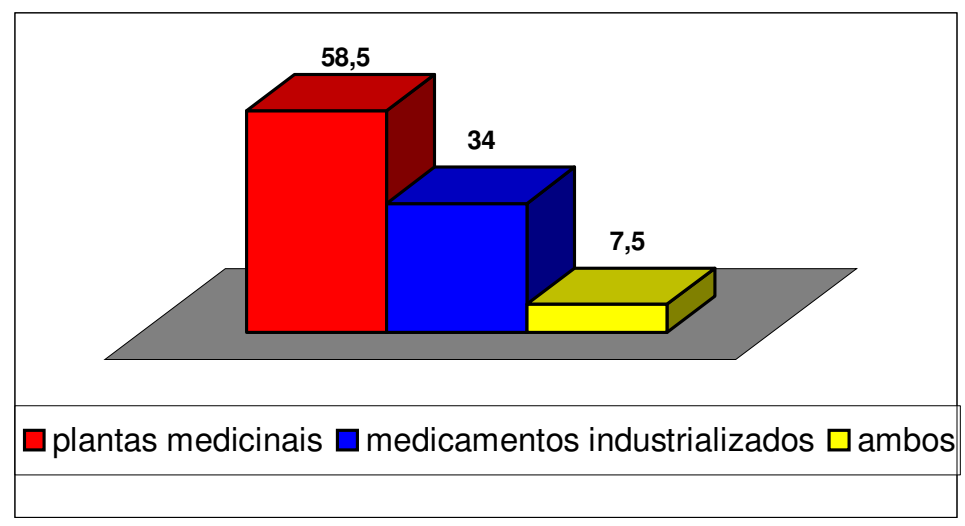

Figura 2. Prioridade na escolha de plantas medicinais

Um ponto interessante na utilização das plantas medicinais é pelo fato da população, em geral, usar os chás como elemento de primeira escolha para o alívio sintomático de suas doenças. Caso a resposta terapêutica seja negativa, recorrem em seguida aos medicamentos industrializados. 


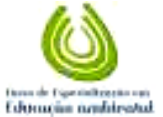

REMOA
FAVILA \& HOPPE, vol.(3), n³, p. 468- 475, 2011.

\section{Monografias Ambientais}

(Revista Eletrônica do Curso de Especialização em Educação Ambiental da UFSM)

"A Organização Mundial da Saúde - OMS estima que $80 \%$ da população de países em desenvolvimento fazem algum tipo de medicina tradicional para cuidados básicos de saúde" (Neves, 2001, p.22).

Questão 3, Acha-se confiante, quanto à posologia das plantas medicinais, sabendo que algumas espécies são tóxicas ao organismo?. Esses dados estão na figura 3.

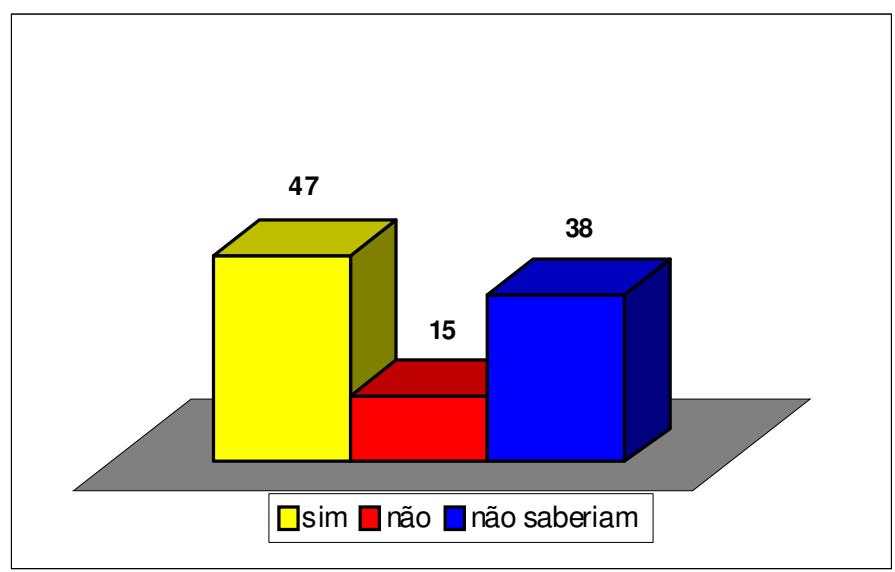

Figura 3. Nível de segurança quanto à dosagem das plantas medicinais

Os dados dessa pergunta não deixam dúvidas que a maioria dos entrevistados pensa saber a dosagem ideal das preparações medicinais, sua identificação botânica e toxicologia. No entanto, os dados referentes às intoxicações por plantas são significativos e demonstram o inverso.

A segurança necessária requer conhecimentos botânicos e consulta as farmacopéias.

A determinação da dose eficaz de uma planta medicinal para uso na forma de chá é empírico, pois, nesta forma não tem-se conhecimento da real concentração dos constituintes ativos. Para esta determinação é necessário fazer um extrato, e neste quantificar a dose correta. Convencionou-se a utilização de três ou quatro folhas da planta "in natura", para administração na forma de chá. Todavia, esse dado não é científico. Em relação aos $38 \%$ que não saberiam informar é bastante significativo, porque indica dúvida quanto ao nível de segurança na dosagem das plantas medicinais.

Em meio ao imenso número de pesquisas com espécies vegetais, salienta-se que as plantas medicinais necessitam de muita atenção quanto à coleta e identificação, em relação aos parâmetros botânicos, no sentido de evitar uma possível intoxicação (Carlini,1983).

Questão 4, O que entende por Educação Ambiental, além da preservação dos ecossistemas? A figura 4 representa os resultados . 


\section{Monografias Ambientais}

REMOA

(Revista Eletrônica do Curso de Especialização em Educação Ambiental da UFSM)

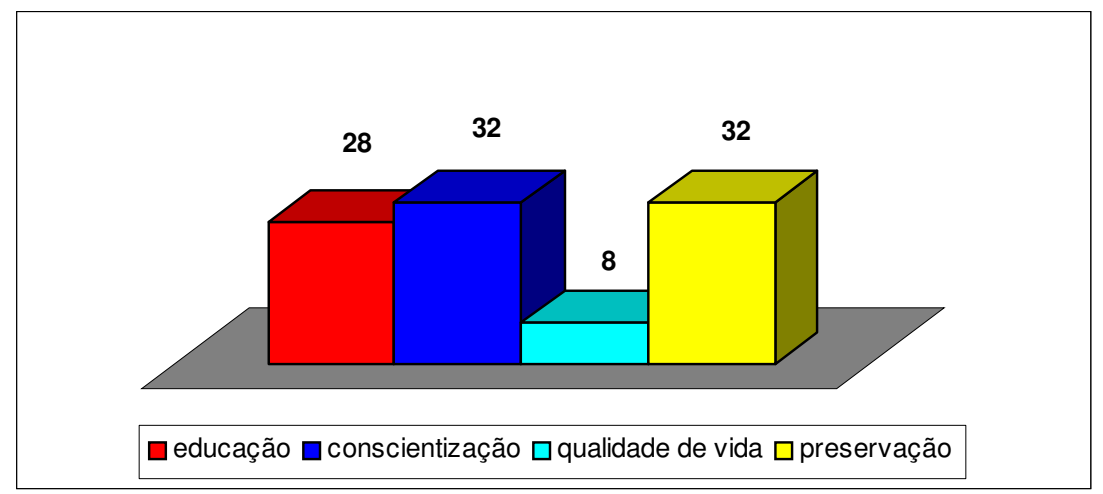

Figura 4. 0 entendimento sobre Educação Ambiental

Esses dados informam que Educação Ambiental é entendida pela maioria como agente sensibilizador no sentido de educar para conscientizar a população na preservação dos ecossistemas naturais o que não deixa de estar correto.

Contudo, apenas $8 \%$ entenderam a abrangência da complexidade ambiental, como segmento inserido nos fatores sociais, étnicos, culturais, primando pela qualidade de vida, como meta fundamental a ser conquistada.

Assim sendo, "O saber ambiental emerge de uma razão crítica, configurando-se em contextos ecológicos, sociais e culturais específicos, e problematizando os paradigmas legitimados e institucionalizados" (Leff, 2001, p.230).

Questão 5, Dê sua opinião enumerando, em ordem de prioridade, as soluções para os problemas ambientais: ( ) Criação de Políticas Públicas, ( ) Educação Ambiental nas escolas, ( ) Sensibilização da população. Esses detalhes são observados na figura 5.

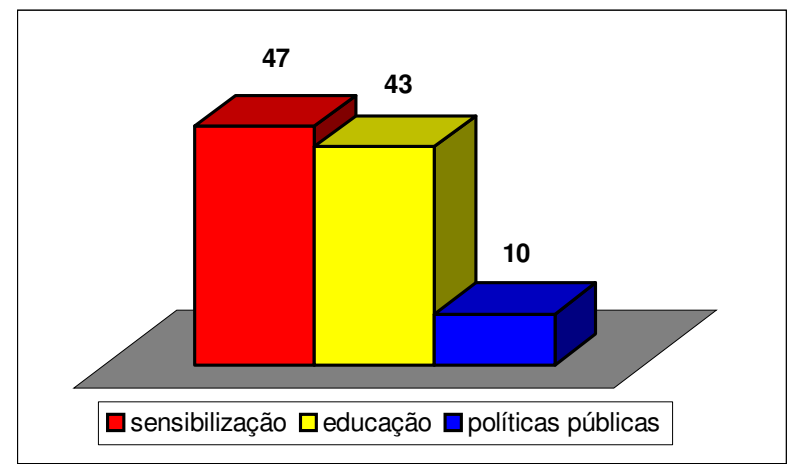

Figura 5. Ordem de prioridade para as soluções ambientais

Segundo os dados referentes a essa questão, os problemas ambientais devem ter uma solução mais concreta quando se investir na sensibilização da população e educação ambiental, tanto no ensino formal quanto no informal.

"A educação Ambiental é um instrumento de conscientização das características perversas dos modelos de desenvolvimento sob ótica social e ambiental..." (Diesel, 1994, p.52).

Em relação às políticas públicas, uma minoria achou ter prioridade, talvez pela falta de credibilidade. Entretanto, para muitas questões ambientais, somente as políticas públicas dão o respaldo necessário atuando efetivamente em situações diversas. 


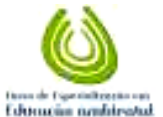

REMOA

FAVILA \& HOPPE, vol.(3), n³, p. 468-475, 2011. Monografias Ambientais

“...as políticas públicas de desenvolvimento, bem como aquelas que partem da iniciativa privada, devem ser exercidas de modo a satisfazerem as necessidades governamentais e ambientais das gerações presentes e futuras" (Araújo, 2000, p.203).

Assim, é necessário criar políticas públicas que favoreçam, efetivamente, a sustentabilidade dos ecossistemas naturais. Em relação às plantas medicinais, há legislação vigente que garante a preservação delas, mediante o replantio. No entanto, a fiscalização torna-se ineficaz frente a imensa variedade vegetal em todo o território nacional. Nesse sentido, cabe aos órgãos competentes criarem medidas que atendam aos interesses ambientais.

\section{CONCLUSÃO}

Um ponto preocupante é demonstrado pelo número expressivo de $47 \%$ acharem-se confiantes na dosagem das plantas medicinais, razão do número significativo de intoxicações, em virtude do desconhecimento das características botânicas e farmacológicas.

É importante salientar que apenas $8 \%$ dos entrevistados compreenderam que a Educação Ambiental está inserida na questão social e tem como finalidade última a qualidade de vida dos povos. Isso denota que o pensamento sobre o conservadorismo está profundamente fundamentado nas idéias da maioria.

\section{BIBLIOGRAFIA}

ARAÚJO, Luiz E. B. Crise e Direito Ambiental . Revista Direito, Santa Cruz do Sul, n.14, jul./dez., 2000.

CANDAU, Vera M. et al. Tecendo a cidadania; oficinas pedagógicas de direitos humanos. Petrópolis, RJ: Vozes, 1995.

CARLINI, E. A Pesquisa com plantas medicinais usadas na medicina popular. Revista Associação Médica Brasileira, v. 29, n. 516, 1983.

CASTRO, H. G, et al. A Dialética do Conhecimento no Uso das Plantas Medicinais. Revista Brasileira de Plantas Medicinais, Botucatu, Ed. FUNDIBIO, v. 3, n. 2, 2001.

CUNHA, Manuela C. da. Saber Tradicional. Folha de São Paulo, São Paulo, 1 dez. 2001.

DIESEL, Vivien. Educação Ambiental: Um tema démodé? Revista Ciência \& Ambiente. Santa Maria: UFSM, n. 8. jan./jun. 1994.

HOSTETTMAN, K., Hamburger, M. Bioactivity in Plants: The link between phytochemistry and Medicine. Phytochemistry, Great Britan, vol. 30, n. 12, 1991.

LAKATOS, Eva Maria. Metodologia Científica. 2. ed. São Paulo: Atlas, 1991.

LEFF, Henrique. O Saber Ambiental: sustentabilidade, racionalidade, complexidade, poder. 1. ed. Petrópolis: vozes, 2001.

. Epistemologia Ambiental. 2. ed. São Paulo: Cortez, 2002.

MATOS, F. J. Abreu. Farmácias Vivas. Fortaleza: Ed. Universidade Federal do Ceará, 2. ed., 1994. 


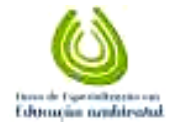

REMOA
FAVILA \& HOPPE, vol.(3), n³, p. 468-475, 2011.

\section{Monografias Ambientais}

(Revista Eletrônica do Curso de Especialização em Educação Ambiental da UFSM)

NASCIMENTO, P. C. Plantas que fazem Mal. Jornal da UNICAMP, Campinas, jun. 2001 - Ano XV, n. 163.

NEVES, Mary. C . M. Plantas Medicinais: diagnóstico e gestão. 2. ed., Brasília: IBAMA, 2001.

NOAL, F.O. et al Tendências da Educação Ambiental Brasileira, Santa Cruz do Sul, Ed. EDUNISC, 1 ed., 1998.

SIMÕES, C.M.O. et al Farmacognosia da Planta ao Medicamento. Ed. UFSC, Ed. Universidade Federal do Rio Grande do Sul, Florianópolis/Porto Alegre, 1. ed., 1999. 